\title{
Effects of Corticotropin Releasing Factor (CRF) on Sleep and Body Temperature Following Controllable Footshock Stress in Mice
}

\author{
L Yang, LL Wellman, $\mathbf{X}$ Tang ${ }^{\star}$, and LD Sanford \\ Eastern Virginia Medical School, Norfolk, VA
}

\section{Abstract}

Rapid eye movement sleep (REM) is increased after controllable stress (modeled by escapable footshock, ES) and decreased after uncontrollable stress (modeled by inescapable footshock, IS). Decreases in REM after IS are exacerbated by corticotropin releasing factor (CRF) and attenuated by a CRF antagonist. In this study, we trained mice with ES following injections of CRF, astressin (AST), or saline (SAL) to determine whether CRF would alter REM after ES. Male BALB/cJ mice $(n=7)$ were implanted for recording sleep, activity and body temperature via telemetry and with a guide cannula aimed into a lateral ventricle. After recovery from surgery, sleep following exposure to a novel chamber was recorded as a handling control (HC). The mice received one day of training with ES without injection followed by weekly training sessions in which they received counterbalanced intracerebroventricular (ICV) microinjections of either SAL or CRF (days 7 \& 14) or SAL or AST (days 21 \& 28) prior to ES. On each experimental day, sleep was recorded for 20 hours. Compared to HC, the mice showed significantly increased REM when receiving either SAL or AST prior to ES whereas CRF prior to ES significantly reduced REM. Stress-induced hyperthermia had longer duration after ES compared to HC, and was not significantly altered by CRF or AST compared to SAL. The current results demonstrate that activity in the central CRF system is an important regulator of stress-induced alterations in REM.

\section{Keywords}

corticotropin releasing factor (CRF); stress; stressor controllability; rapid eye movement sleep (REM); sleep; body temperature; mice

\subsection{Introduction}

The corticotropin factor (CRF) system [1-5] and fear conditioning [6-8] have prominent places in current ideas regarding the development of anxiety disorders, including posttraumatic stress disorder (PTSD). Altered sleep in the aftermath of a traumatic event also is

\footnotetext{
(C) 2011 Elsevier Inc. All rights reserved.

Corresponding Author: Larry D. Sanford, Sleep Research Laboratory, Department of Pathology and Anatomy, Eastern Virginia Medical School, P.O. Box 1980, Norfolk, VA 23501. TEL @ 7757) 446-7081, FAX @ 757) 446-5719, sanforld@evms.edu.

Present address : Sleep Medicine Center, West China Hospital of Scihuan University, Chengdu City, Sichuan Province, China 610041
}

Publisher's Disclaimer: This is a PDF file of an unedited manuscript that has been accepted for publication. As a service to our customers we are providing this early version of the manuscript. The manuscript will undergo copyediting, typesetting, and review of the resulting proof before it is published in its final citable form. Please note that during the production process errors may be discovered which could affect the content, and all legal disclaimers that apply to the journal pertain. 
thought to play a role in PTSD and continuing difficulties in sleep after significant stress appear to be predictive of future development of emotional and physical disorders [9-11].

Several lines of evidence indicate a major role for CRF in mediating central nervous system responses to stressors [12-17]. Intracerebroventricular (ICV) administration of CRF in rats produces many of the signs associated with anxiety in humans, including increased wakefulness [18-21], altered locomotor activity, and an exaggerated startle response [22, 23]. By comparison, CRF antagonists attenuate behavioral responses to stress (e.g., [24-27]).

CRF also has been implicated in the regulation of wakefulness and sleep in both stressful and non-stressful situations. For example, administration of CRF antagonists have been reported to eliminate rapid eye movement sleep (REM) rebound after immobilization stress [28]. In the absence of stressors, CRF contributes to the regulation of spontaneous waking [20, 29-31], and interestingly, both administration of CRF [32] and the non-specific CRF antagonist, $\alpha \mathrm{HelCRF}$ ( $\alpha$-helical $\mathrm{CRH}_{9-41}$ ) [33], have been reported to reduce the amount of REM recovery after sleep deprivation.

Fear conditioning with inescapable shock (IS), an uncontrollable stressor, and the presentation of fearful contexts and cues associated with IS are followed by significant reductions in REM that occur in the first few hours after exposure [34-37]. In mice, ICV administration of CRF enhances the reduction in REM following fearful contexts whereas ICV administration of the non-specific CRF antagonist, astressin (AST), attenuates fearinduced reductions in REM [38]. In general, the available evidence suggest that central CRF plays a significant role in regulating stress-induced alterations in REM, including the reductions produced by contextual fear associated with IS training.

In comparison to training with IS, sleep following training with escapable shock (ES), in which a mouse always receives shock but is able to terminate it with a simple escape response, can be characterized by enhancements in REM [39]. To determine whether central CRF plays a role in regulating alterations in REM following ES, we trained mice in a multitrial ES stress paradigm and administered CRF, AST, or saline (SAL) control alone, prior to ES and recorded post-exposure sleep. We conducted the study in "behaviorally reactive" $\mathrm{BALB} / \mathrm{cJ}$ mice which show greater post-stress reductions in REM and alterations in sleep compared to C57BL/6J mice [35, 36, 40] and which also show greater alterations in sleep in response to CRF administered ICV [41]. We also examined the effects of CRF on stressinduced hyperthermia (SIH), an increase in core body temperature that follows both physiological and psychological stress [42].

\section{Materials and Methods}

\subsection{Subjects}

The subjects were $7 \mathrm{male} \mathrm{BALB} / \mathrm{c} / \mathrm{J}$ mice weighing 22 to $25 \mathrm{~g}$ at the time of surgery. All animals were obtained from the Jackson Laboratory, Bar Harbor, Maine. The animals were individually housed after arrival and food and water were available ad libitum. The recording room was kept on a 12:12-h light:dark cycle with lights on from 07:00 to 19:00. Ambient temperature was maintained at $24.5^{\circ} \mathrm{C} \pm 0.5^{\circ}$.

\subsection{Surgery}

All mice were implanted intraperitoneally with telemetry transmitters (DataSciences ETA 10-F20) for recording EEG, body temperature and activity as previously described [43]. EEG leads from the transmitter body were led subcutaneously to the head, and the free ends were placed into holes drilled in the dorsal skull to allow recording cortical EEG. In the same surgery, the mice were stereotaxically implanted with a cannula to allow 
intracerebroventricular (ICV) microinjections. A hole was drilled in the skull $1.00 \mathrm{~mm}$ lateral and $0.5 \mathrm{~mm}$ posterior to Bregma and the tip of a 26-gauge stainless steel infusion cannula was placed $2.00 \mathrm{~mm}$ below the skull surface into the right ventricle. The cannula was secured to the skull with dental cement and a stylus was inserted to maintain patency. All surgeries were performed under aseptic conditions and with the mice under isoflurane (as inhalant: 5\% induction; 1 - 2\% maintenance) anesthesia. Ibuprofen (30 mg/kg, orally) was continuously available in each animal's drinking water for 24 to $48 \mathrm{~h}$ preoperatively and for a minimum of $72 \mathrm{~h}$ postoperatively to alleviate potential postoperative pain. Antibiotics (gentamicin $5-8 \mathrm{mg} / \mathrm{kg}$ and Procaine penicillin 100,000 IU/kg) were given subcutaneously preoperatively to prevent infection. Dexamethazone $(0.4 \mathrm{mg}(0.2 \mathrm{ml}$ total dosage $))$ was administered subcutaneously preoperatively to reduce brain swelling. All procedures were conducted in accordance with the National Institutes of Health Guide for the Care and Use of Experimental Animals and were approved by Eastern Virginia Medical School's Animal Care and Use Committee (Protocol \# 05 - 017 and 08 - 007).

\subsection{Experimental Procedures}

The mice were housed and studied in the same room. Cages and bedding were changed 2 days prior to recording onset for each phase of the experiment and then not disturbed until that phase was complete. ICV location of the cannula was verified with administration of angiotensin II (50 ng in $0.2 \mu \mathrm{l} \mathrm{ICV)} \mathrm{and} \mathrm{observation} \mathrm{for} \mathrm{drinking.} \mathrm{A} \mathrm{positive} \mathrm{angiotensin-}$ induced drinking response was shown by all mice included in the study.

The mice were allowed a post-surgery recovery period of 19-20 days prior to beginning the experiment. Undisturbed baseline recordings were then obtained for two days. Afterwards, the mice were habituated to two daily sessions of the handling procedures needed for administering microinjections. Sleep also was recorded following exposure to a novel chamber (an enclosure of approximately the same dimensions as the shock chambers $(20 \times$ $40 \times 30 \mathrm{~cm}$ )) with an open top and walls and floor constructed of clear Plexiglas ${ }^{\mathrm{TM}}$. This recording session controlled for handling and exposure to a non-cage environment and was used as a handling control (HC) for comparisons across treatment conditions.

For training with ES, the mice were placed into in a shuttlebox (Coulbourn Instruments, Model E10-15SC) and were allowed to freely explore for $5 \mathrm{~min}$. The mice were then were presented with 20 footshocks ( $0.5 \mathrm{~mA}, 5.0 \mathrm{sec}$ maximum duration) at 1.0-min intervals. During shock presentation, the mice were able to escape by moving to the non-occupied chamber in the shuttlebox. Five min after the last shock, the mice were returned to their home cages. The entire procedure was of approximately 30 -min duration and occurred during the fourth hour of the lights-on period. Between each training session, the floor trays in the shock chambers were removed and cleaned with $30 \%$ alcohol. The shock grid, walls, and doors of the shock chambers were also cleaned with $30 \%$ alcohol and then dried with a paper tower if necessary.

The mice received 1 day of training with ES and handling prior to beginning the microinjection studies to provide the mice an opportunity to learn the escape response. At weekly intervals after the training day, the mice received counterbalanced ICV microinjections of either saline (SAL) or CRF prior to ES or SAL or astressin (AST) prior to ES. The mice received identical periods of brief restraint associated with administering the injections prior to all experimental sessions.

\subsection{Drugs and Microinjections}

CRF and AST (cyclo(33)[D-Phe12,N1e21,38,Glu30,Lys33] h/ rCRF(12-41)) were obtained in powder form from Sigma-Aldrich (St. Louis, MO) and were diluted to the desired 
concentrations in pyrogen-free saline (SAL). CRF $0.2 \mu \mathrm{g}(0.21 \mathrm{mM})$, AST $0.4 \mu \mathrm{g}(0.56 \mathrm{mM})$ or SAL alone $(0.2 \mu \mathrm{l})$ were administered during the fourth hour of lights on.

For microinjections, an injection cannula ( $33 \mathrm{ga}$.), which projected $1.0 \mathrm{~mm}$ beyond the tip of the guide cannula, was secured in place. The injection cannula was connected to a $50 \mathrm{~cm}-$ length of polyethylene tubing that had been pre-filled with the solution to be injected. The microinjection was carried out using a $5.0 \mu \mathrm{l}$ Hamilton syringe which had been pre-filled with distilled water. An air bubble was allowed to form in the tubing line close to the syringe end so that fluid movement could be verified as well as the solution could be separated from distilled water. The solutions in a volume of $0.2 \mu \mathrm{l}$ were infused over $1 \mathrm{~min}$. After receiving the injections, the mice were returned to their home cages for 15 minutes prior to training.

\subsection{Data Recording and Determination of Behavioral State}

EEG, body temperature and activity data were collected for $20 \mathrm{~h}$ ( $8 \mathrm{~h}$ light and $12 \mathrm{~h}$ dark) on the HC day and on each day a microinjection was administered. For recording, individual cages were placed on a DataSciences telemetry receiver (RPC -1) and the transmitters for the mice were activated with a magnetic switch. When the animals were not on study, the transmitters were inactivated. Signals (EEG, body temperature and activity) from the transmitter were detected by a receiver located directly underneath the cage. These signals were processed by DataSciences software and saved to the hard disk for subsequent off line data analyses and for visual determination of sleep and wakefulness in 10-s epochs using the SleepSign ${ }^{\mathrm{TM}}$ scoring program.

Epochs were scored by a trained observer as either active wakefulness (AW, activity recorded in epoch), quiet wakefulness (QW, no activity in epoch), NREM, or REM based on EEG and gross whole body activity as previously described [43]. Transistor-transistor logic (TTL) pulses generated by the telemetry system when the mice moved around in their cages were counted as a measure of activity. This method provides only a measure of general activity and typically requires gross body movement in order to generate a count. Core body temperature also was automatically recorded by the intraperitoneally implanted transmitter.

\subsection{Data Analyses}

The following sleep parameters were evaluated for the 20-total $\mathrm{h}$ recording period: time in active wakefulness (AW) and quiet wakefulness (QW), episodes of wakefulness, episode duration of wakefulness, time in REM sleep, number of REM episodes, REM sleep duration, REM sleep percentage ([total REM / total sleep time (TST)] * 100), time in NREM sleep, number of NREM episodes, NREM sleep duration and TST. The latencies to the first episodes of NREM and REM were also examined. The two SAL recording days did not differ significantly and were averaged for comparisons across conditions. The data were analyzed with one way repeated measure analyses of variance (ANOVA) across treatment conditions.

The data for the body temperature were analyzed hourly for the initial 4 hours of the total 20-h recording period using mixed factors ANOVA with repeated measures on treatment (HC, SAL-ES, CRF-ES and AST-ES) x time (h 1-4). The temperature data were also analyzed considered as differences relative to time-matched non-stress baseline. These data were examined in 10-min blocks for the first 2 hours.

Statistical analyses were conducted using SigmaStat V2.03 (SPSS, Inc. Chicago, IL). When indicated by a significant ANOVA, post hoc comparisons among means were conducted with Tukey tests. The data on latencies to the first episodes of REM failed the normality test and were analyzed with a Friedman repeated measures ANOVA on Ranks. 


\subsection{Results}

\subsection{Effects of CRF and AST on ES-induced alterations in REM}

The analysis of total REM over the $20 \mathrm{~h}$ total recording periods (Figure $1 \mathrm{~A}$ ) revealed a significant main effect for treatment $(F 3,18=31.96, \mathrm{p}<0.0000002)$. REM was significantly decreased on the CRF-ES recording day compared to HC ( $\mathrm{p}=0.0007)$, SAL-ES ( $\mathrm{p}$ $0.0002)$ and AST-ES $(\mathrm{p}<0.0002)$. The mice also showed significantly increased REM on SAL-ES compared to HC ( $p<0.007)$. Total REM on the SAL-ES and AST-ES recording days did not significantly differ.

The ANOVA for REM percentage (Figure $1 \mathrm{~B}$ ) revealed similar results to those found for total REM. There was a significant main effect for treatment $(F 3,18=16.95, \mathrm{p}<0.00002)$. Post hoc tests found that CRF-ES significantly decreased REM percentage compared to HC ( $\mathrm{p}<0.008)$, SAL-ES ( $\mathrm{p}<0.0002)$ and AST-ES $(\mathrm{p}<0.0002)$. REM percentage on the HC, SAL-ES and AST-ES treatment days did not significantly differ.

The analysis for the number of REM episodes (Figure $1 \mathrm{C}$ ) found a significant main effect for treatment $(F 3,18=9.33, \mathrm{p}<0.0007)$. The number of REM episodes was significantly decreased on the CRF-ES recording day compared to HC ( $p<0.02)$, SAL-ES ( $p<0.0008)$ and AST-ES ( $p<0.004)$. The number of REM episodes did not significantly differ across HC, SAL-ES or AST-ES treatment days.

The analysis for the REM episode duration (Figure $1 \mathrm{D}$ ) found a significant main effect for treatment $(F 3,18=3.39, \mathrm{p}<0.05)$. The duration of REM episodes was significantly decreased on the CRF-ES recording day compared to AST-ES ( $p<0.05$ ). No other comparisons were significant.

The analysis of the latencies to the REM (HC: $65.88 \pm 7.35$; SAL-ES: $129.37 \pm 27.39$; CRFES: $148.57 \pm 25.95$; AST-ES: $155.69 \pm 63.95)$ revealed a significant difference across treatment conditions $\left(\chi^{2}=12.77\right.$ with 3 degrees of freedom, $\left.p<0.006\right)$. Post hoc analysis indicated that mice had significantly longer latencies to REM after receiving microinjection of CRF compared to HC ( $p<0.05)$. No other comparisons were significant.

\subsection{Effects of CRF and AST on ES-induced alterations in NREM, Total Sleep Time and Wakefulness}

Total NREM (Figure $2 \mathrm{~A}$ ) and total sleep time (Figure 2 B) did not significantly differ across treatment condition. We also found no significant difference across condition for the number of NREM episodes or NREM episode duration (data not shown). The latencies to NREM (HC: $36.67 \pm 6.32$; SAL-ES: 51.57 \pm 9.09 ; CRF-ES: 47.81 \pm 12.04 ; AST-ES: $39.33 \pm 10.26)$ did not significantly differ across treatments.

Time in AW (Figure $2 \mathrm{C}$ ) did not differ across treatment conditions. However, the analysis for QW (Figure 2 D) showed a significant main effect for treatment $(F 3,18=4.10, \mathrm{p}<0.02)$. $\mathrm{QW}$ was reduced on SAL-ES compared to HC ( $\mathrm{p}<0.03)$. The comparison of AST-ES and $\mathrm{HC}$ did not reach significance $(\mathrm{p}<0.06$ ). No other significant differences were found in the parameters of wakefulness we examined.

\subsection{Effects of CRF and AST on ES-induced alterations in core body temperature}

We examined changes in core body temperature hourly across the first $4 \mathrm{~h}$ of recording to assess potential differences in SIH (Figure 3). The ANOVA revealed a main effect for treatment $(F 3,18=8.72, \mathrm{p}<0.0009)$. Compared to $\mathrm{HC}$, core body temperature was significantly increased during h $1-3$ after SAL-ES and for h $1-4$ after CRF-ES. In 
contrast, compared to HC, significant increases in core body temperature after AST-ES were observed only in h 2 .

To more closely examine the conditions for potential differences in SIH, we also analyzed the percentage changes in core body temperature for HC, SAL-ES, CRF-ES and AST-ES relative to time-matched uninterrupted baseline recordings in 10-min intervals over the first $2 \mathrm{~h}$ of recording (Figure 4). The ANOVA showed a main effect for treatment $(F 3,18=8.35$, $\mathrm{p}=0.001)$. In general, relative to baseline, the mice showed an increase in core body temperature from the first to fifth 10 -min intervals $(\min 10-50)$ in each treatment condition. However, core body temperature after $\mathrm{HC}$ returned to baseline levels by the end of the first $h$. Thereafter, compared to HC, mice showed significant increases in core body temperature after SAL-ES from 50 - 120 minutes; CRF-ES from 40 - 120 minutes and AST-ES from 50 - 100 minutes.

\subsection{Discussion}

The current results demonstrate that ES, preceded by microinjections of either SAL or AST, produces similar, significant enhancements in post-stress REM relative to a non-shocked HC condition. The enhancement of REM by ES was blocked by pretreatment with CRF and the effect was relatively specific for REM as changes in NREM and wakefulness were minimal. However, even though post-stress REM could be increased or decreased depending on treatment, a similar initial stress response, as indicated by $\mathrm{SIH}$, was elicited by across all shock and microinjection treatments.

\subsection{CRF and Stress-induced Alterations in Sleep}

ICV administration of CRF can decrease REM in non-stressed BALB/c mice; however it also produces increases in wakefulness and decreases in NREM [41]. CRF can also exacerbate decreases in REM produced by fearful contexts associated with IS [38]. By comparison, AST can decrease active wakefulness and increase REM in non-stressed $\mathrm{BALB} / \mathrm{c}$ mice [41] and it can attenuate the decrease in REM following exposure to contexts made fearful by IS [38]. In the current study, CRF administered to mice receiving ES resulted in significant reductions in REM whereas AST did not significantly alter REM compared to SAL alone. Together, these findings suggest that CRF plays a significant role in stress-induced alterations in REM and that the central CRF system is differentially modulated by controllable and uncontrollable stress, as modeled by ES and fear associated with IS.

There have been few previous studies examining the role of CRF in regulating stressinduced alterations in sleep, and these have yielded conflicting data. Some authors have reported that restraint stress applied at the onset of the dark period induces a subsequent increase in sleep, in particular, REM [44]. The ICV administration of $\alpha$ HelCRF prior to restraint stress prevented the subsequent increase in REM, but did not alter spontaneous REM, NREM or wakefulness in non-stressed animals [28]. In contrast, other investigators found no effect of restraint stress applied at the beginning of the dark period on subsequent sleep, and also found no effect of AST on sleep after restraint [45]. By comparison, restraint administered at the onset of the light period increased wakefulness and decreased both NREM and REM, and ICV administration of AST attenuated the increase in wakefulness over a five hour period immediately after restraint was removed [45]. There may have been differences in the procedures used for restraint (e.g., whether or not it was conducted in the home cage [45]) that could have accounted for different results in these studies. The results of studies with restraint (CRF antagonist blocks post-stress increase in REM [28]) and contextual fear (CRF antagonist blocks post-fear decrease in REM [38]) may appear to be in conflict. However, in both types of studies, the antagonist was administered prior to 
exposure to the stressor and simply may have prevented or attenuated the CRF response to the stressor which altered subsequent post-stress sleep.

A recent study [46] examined baseline and recovery sleep after sleep deprivation in conditional mouse mutants that overexpress CRF in the entire central nervous system or only in the forebrain including limbic structures. In baseline recordings, homozygous mice with either global or forebrain overexpression of CRF showed increased REM compared to controls and both homozygous and heterozygous mice with global overexpression of CRF showed enhanced recovery REM after $6 \mathrm{~h}$ sleep deprivation. Enhanced REM recovery, but not NREM recovery, was blocked by oral administration of the CRF receptor type 1 (CRFR1) antagonist, DMP696, one h prior to the end of sleep deprivation. Peripheral stress hormone levels were not elevated during baseline and did not differ across genotypes after sleep deprivation. The authors concluded that enhanced REM in these mice was most likely induced through the activation of CRFR1. These data add to the puzzle regarding the role of CRF in regulating REM and stress-induced alterations in REM. For instance, we have found that microinjections of the CRFR1 antagonist, antalarmin, into the central nucleus of the amygdala in rats block fear-induced reductions in REM and attenuate Fos expression, a maker of neural activation, in regions important in stress and REM regulation including the hypothalamic paraventricular nucleus (PVN), locus coeruleus (LC), and dorsal raphe nucleus (DRN) [47]. Similarly, microinjections of antalarmin into the basal nucleus of the amygdala in rats blocked the reduction in REM produced by inescapable footshock [48]. CRF also activates brainstem regions inhibitory to REM (see discussion below). These findings, as well as the current results, are consistent with inhibition of REM after activation of CRFR1. Thus, currently existing data demonstrate that the role(s) of the CRF system in regulating REM are complex and can be site dependent. The time course of increased activity in the CRF system and subsequent return to normal levels is likely also important for the effects of CRF on REM.

\subsection{Stress-induced Hyperthermia}

The time course of SIH parallels that of HPA activation $[49,50]$. SIH is stable across repeated presentations of a stressor [42] and can occur rapidly. For example, handling stress, exposure to novel environments or restraint can raise core temperature as much as $2^{\circ} \mathrm{C}$ in rats and mice [51-54] and increases can begin within $10 \mathrm{~s}$ of the onset of stress induction $[54,55]$.

SIH is sensitive to anxiolytic drugs, but not anxiogenic drugs possibly due to ceiling effects of the stress-induced increase in temperature, i.e., there is a maximum limit to the temperature increase [42]. In the current study, all treatment conditions showed significantly increased average body temperature relative to time matched baseline (SAL-ES: $1.7^{\circ}$; CRFES: $1.8^{\circ}$; AST-ES: $1.5^{\circ}$ and $\mathrm{HC}: 0.9^{\circ} \mathrm{C}$ increase over bas eline) during the first hour after being returned to their home cages. These data suggest that this component of the initial stress response was relatively similar across conditions even though post-stress sleep could differ. Though, SIH after HC, putatively a milder stressor, returned to baseline levels within the first $\mathrm{h}$, increased body temperature after injection of CRF persisted for 4 hours $\left(0.9-1.4^{\circ}\right.$ $\mathrm{C}$ higher than $\mathrm{HC}$ ) and after injection of SAL for 3 hours (range of $0.7-1.2^{\circ} \mathrm{C}$ higher than $\mathrm{HC})$. By comparison, after injection of AST temperature was increased relative to $\mathrm{HC}$ only in the second hour $\left(0.9^{\circ} \mathrm{C}\right.$ higher than $\left.\mathrm{HC}\right)$.

We previously demonstrated that signaled ES and signaled IS in mice produced similar increases and time courses of SIH [39]. Thus, it was not surprising that core body temperature was increased after ES in the present study, or that the time course of SIH after ES was of greater duration than SIH after HC. Although CRF given ICV can increase body temperature [56], given the potential ceiling effect in SIH [42], the lack of a further increase 
after CRF also was expected. Somewhat more surprising was that AST did not produce a greater attenuation of SIH. In rats, ICV administration of $\alpha \mathrm{HelCRH}$ reduced body temperature and other markers of stress including blood pressure, heart rate, and locomotive activity after exposure to a cage change stressor [56, 57]. In vitro assays indicate that AST is more potent for both CRF1 and CRF2 receptors than is $\alpha \mathrm{HelCRH}$, yet does not have its partial agonist properties [58]. However, in vivo studies in rats suggest that AST may be somewhat less potent in preventing some CRF- and stress-induced and anxiety-related behaviors [24]. This potential reduced efficacy for some stress variables and the fact that cage change also is likely a less intense stressor than ES may account for the differences. This is suggested by the fact that the increase in body temperature in rats after cage change was around $0.5^{\circ} \mathrm{C}$ [56] co mpared to the greater increases we observed in mice after ES. $\mathrm{SIH}$ after $\mathrm{HC}$ had a more rapid return to non-stress levels also suggesting a less intense initial stress response.

\subsection{Potential Neural Basis of Stress-induced Alterations in Sleep}

The locus coeruleus (LC) and dorsal raphe nucleus (DRN), two brainstem regions long implicated in the regulation of REM [59], are critical regions for mediating the central effects of CRF. For example, the application of CRF to LC increases noradrenaline (NA) release [60], and in DRN, microinjection of CRF in the absence of IS produces effects similar to IS whereas microinjection of a CRF antagonist blocks the behavioral effects of IS [61-63].

Brainstem serotonergic [64-66] and noradrenergic [67] regions also appear to play important roles in stressor controllability. Yoked C57BL/6 mice receiving IS showed greater Fos activation in the LC and DRN than did mice trained with ES [68]. Yoked control rats also showed higher Fos expression in DRN than did rats that were able to terminate shock via turning a wheel [64]. IS in rats also activates 5-HT DRN neurons to a greater degree than does ES thereby increasing 5-HT in DRN and in target areas [65, 66]. IS in rats produced sustained increases in NA turnover in various brain regions regardless of stress duration, whereas with ES, NA utilization was reduced after the coping response was learned [67]. Given their putative role in regulating REM [59], the relative level of activation of LC and DRN may be important for the differential amounts of REM seen after ES and IS.

\subsection{Conclusions}

Controllability is a significant factor for successful coping with stress $[69,70]$ and lack of stressor controllability has been linked to the development of PTSD [6] and other psychiatric disorders $[71,72]$. Stress-induced disturbances in sleep also have been linked to the development of psychopathology $[10,11,73]$. Together with previous findings that AST blocked fear-induced reductions in REM [38], the present results demonstrate that stressinduced alterations in central CRF can vary with stressor controllability and are important for the types of sleep that occur in the post-stress period. This suggests that the central CRF system may be a significant determinant of the role sleep plays in adaptive and non-adaptive responding to stress.

\section{Acknowledgments}

This work was by supported by NIH research grants MH61716 and MH64827.

\section{References}

1. Baker DG, et al. Serial CSF corticotropin-releasing hormone levels and adrenocortical activity in combat veterans with posttraumatic stress disorder. Am J Psychiatry. 1999; 156(4):585-8. [PubMed: 10200738] 
2. Bremner J, et al. Elevated CSF corticotropin-releasing factor concentrations in posttraumatic stress disorder. Am J Psychiatry. 1997; 154:624-629. [PubMed: 9137116]

3. de Kloet CS, et al. Elevated plasma corticotrophin-releasing hormone levels in veterans with posttraumatic stress disorder. Prog Brain Res. 2007; 167:287-91. [PubMed: 18037027]

4. Neylan TC, et al. Neuroendocrine regulation of sleep disturbances in PTSD. Ann N Y Acad Sci. 2006; 1071:203-15. [PubMed: 16891571]

5. Sautter FJ, et al. Corticotropin-releasing factor in posttraumatic stress disorder (PTSD) with secondary psychotic symptoms, nonpsychotic PTSD, and healthy control subjects. Biol Psychiatry. 2003; 54(12):1382-8. [PubMed: 14675802]

6. Foa EB, Zinbarg R, Rothbaum BO. Uncontrollability and unpredictability in posttraumatic stress disorder: an animal model. Psychol Bull. 1992; 112(2):218-38. [PubMed: 1454893]

7. Grillon C, Southwick SM, Charney DS. The psychobiological basis of posttraumatic stress disorder. Mol Psychiatry. 1996; 1(4):278-97. [PubMed: 9118351]

8. Shalev AY, Ragel-Fuchs Y, Pitman RK. Conditioned fear and psychological trauma. Biol Psychiatry. 1992; 31(9):863-5. [PubMed: 1637927]

9. Koren D, et al. Sleep complaints as early predictors of posttraumatic stress disorder: a 1-year prospective study of injured survivors of motor vehicle accidents. Am J Psychiatry. 2002; 159:855857. [PubMed: 11986142]

10. Lavie P. Sleep disturbances in the wake of traumatic events. N Engl J Med. 2001; 345(25):182532. [PubMed: 11752360]

11. Mellman TA, et al. REM sleep and the early development of posttraumatic stress disorder. Am J Psychiatry. 2002; 159(10):1696-701. [PubMed: 12359675]

12. Deussing JM, Wurst W. Dissecting the genetic effect of the CRH system on anxiety and stressrelated behaviour. C R Biol. 2005; 328(2):199-212. [PubMed: 15771006]

13. Koob GF. Corticotropin-releasing factor, norepinephrine, and stress. Biol Psychiatry. 1999; 46(9): 1167-80. [PubMed: 10560023]

14. Koob GF, Heinrichs SC. A role for corticotropin releasing factor and urocortin in behavioral responses to stressors. Brain Res. 1999; 848(1-2):141-52. [PubMed: 10612706]

15. Bakshi VP, Kalin NH. Corticotropin-releasing hormone and animal models of anxiety: geneenvironment interactions. Biol Psychiatry. 2000; 48(12):1175-98. [PubMed: 11137059]

16. Heinrichs SC, et al. The role of CRF in behavioral aspects of stress. Ann N Y Acad Sci. 1995; 771:92-104. [PubMed: 8597448]

17. Koob G, Bloom F. Corticotropin-releasing factor and behavior. Fed Proc. 1985; 44:259-263. [PubMed: 3871412]

18. Ehlers CL, Reed TK, Henriksen SJ. Effects of corticotropin-releasing factor and growth hormonereleasing factor on sleep and activity in rats. Neuroendocrinology. 1986; 42(6):467-74. [PubMed: 3084988]

19. Marrosu F, et al. Corticotropin-releasing factor (CRF) increases paradoxical sleep (PS) rebound in PS-deprived rats. Brain Res. 1990; 515(1-2):315-8. [PubMed: 2357570]

20. Chang FC, Opp MR. Blockade of corticotropin-releasing hormone receptors reduces spontaneous waking in the rat. Am J Physiol. 1998; 275(3 Pt 2):R793-802. [PubMed: 9728077]

21. Chang FC, Opp MR. Pituitary CRH receptor blockade reduces waking in the rat. Physiology \& behavior. 1999; 67(5):691-6. [PubMed: 10604839]

22. Heilig M, et al. Corticotropin-releasing factor and neuropeptide $\mathrm{Y}$ : role in emotional integration. Trends Neurosci. 1994; 17(2):80-5. [PubMed: 7512773]

23. Swerdlow NR, et al. Corticotropin-releasing factor potentiates acoustic startle in rats: blockade by chlordiazepoxide. Psychopharmacology (Berl). 1986; 88(2):147-52. [PubMed: 3081925]

24. Spina MG, et al. Behavioral effects of central administration of the novel CRF antagonist astressin in rats. Neuropsychopharmacology. 2000; 22(3):230-9. [PubMed: 10693150]

25. Aloisi AM, et al. Neuroendocrine and behavioral effects of CRH blockade and stress in male rats. Physiol Behav. 1999; 66(3):523-8. [PubMed: 10357444] 
26. Basso AM, et al. Corticotropin-releasing factor antagonist attenuates the "anxiogenic-like" effect in the defensive burying paradigm but not in the elevated plus-maze following chronic cocaine in rats. Psychopharmacology (Berl). 1999; 145(1):21-30. [PubMed: 10445369]

27. Deak T, et al. Evidence that brief stress may induce the acute phase response in rats. Am J Physiol. 1997; 273(6 Pt 2):R1998-2004. [PubMed: 9435654]

28. Gonzalez MM, Valatx JL. Effect of intracerebroventricular administration of alpha-helical CRH (9-41) on the sleep/waking cycle in rats under normal conditions or after subjection to an acute stressful stimulus. J Sleep Res. 1997; 6(3):164-70. [PubMed: 9358394]

29. Chang FC, Opp MR. Corticotropin-releasing hormone (CRH) as a regulator of waking. Neurosci Biobehav Rev. 2001; 25(5):445-53. [PubMed: 11566481]

30. Opp MR. Corticotropin-releasing hormone involvement in stressor-induced alterations in sleep and in the regulation of waking. Adv Neuroimmunol. 1995; 5(2):127-43. [PubMed: 7496608]

31. Opp MR. Rat strain differences suggest a role for corticotropin-releasing hormone in modulating sleep. Physiology \& behavior. 1997; 63(1):67-74. [PubMed: 9402617]

32. Schussler P, et al. Growth hormone-releasing hormone and corticotropin-releasing hormone enhance non-rapid-eye-movement sleep after sleep deprivation. Am J Physiol Endocrinol Metab. 2006; 291(3):E549-56. [PubMed: 16912060]

33. Gonzalez MM, Valatx JL. Involvement of stress in the sleep rebound mechanism induced by sleep deprivation in the rat: use of alpha-helical CRH (9-41). Behav Pharmacol. 1998; 9(8):655-62. [PubMed: 9890255]

34. Pawlyk AC, et al. A rodent model of sleep disturbances in posttraumatic stress disorder: The role of context after fear conditioning. Biol Psychiatry. 2005; 57(3):268-77. [PubMed: 15691528]

35. Sanford LD, et al. Influence of shock training and explicit fear-conditioned cues on sleep architecture in mice: strain comparison. Behav Genet. 2003; 33(1):43-58. [PubMed: 12645821]

36. Sanford LD, Yang L, Tang X. Influence of contextual fear on sleep in mice: a strain comparison. Sleep. 2003; 26(5):527-40. [PubMed: 12938805]

37. Sanford LD, Fang J, Tang X. Sleep after differing amounts of conditioned fear training in BALB/ cJ mice. Behav Brain Res. 2003; 147(1-2):193-202. [PubMed: 14659585]

38. Yang $\mathrm{L}$, et al. Corticotropin releasing factor (CRF) modulates fear-induced alterations in sleep in mice. Brain Res. 2009; 1276:112-22. [PubMed: 19376095]

39. Sanford LD, et al. Differential effects of controllable and uncontrollable footshock stress on sleep in mice. Sleep. 2010; 33(5):621-30. [PubMed: 20469804]

40. Tang X, et al. Strain differences in the influence of open field exposure on sleep in mice. Behav Brain Res. 2004; 154(1):137-47. [PubMed: 15302119]

41. Sanford LD, et al. Mouse strain differences in the effects of corticotropin releasing hormone (CRH) on sleep and wakefulness. Brain Res. 2008; 1190:94-104. [PubMed: 18053970]

42. Vinckers, CH., et al. Stress-induced hyperthermia in the mouse. In: Gould, TD., editor. Mood and Anxiety-related Phenotypes in Mice: Characterization Using Behavioral Tests. Humana Press; New York: 2009. p. 139-152.

43. Tang X, Sanford LD. Telemetric recording of sleep and home cage activity in mice. Sleep. 2002; 25(6):691-9. [PubMed: 12224849]

44. Rampin C, et al. Immobilisation stress induces a paradoxical sleep rebound in rat. Neurosci Lett. 1991; 126(2):113-8. [PubMed: 1922920]

45. Chang FC, Opp MR. Role of corticotropin-releasing hormone in stressor-induced alterations of sleep in rat. Am J Physiol Regul Integr Comp Physiol. 2002; 283(2):R400-7. [PubMed: 12121853]

46. Kimura M, et al. Conditional corticotropin-releasing hormone overexpression in the mouse forebrain enhances rapid eye movement sleep. Mol Psychiatry. 2010; 15(2):154-65. [PubMed: 19455148]

47. Liu X, et al. Antagonizing Corticotropin Releasing Factor in the Central Nucleus of the Amygdala Attenuates Fear-induced Reductions in Sleep but not Freezing. SLEEP. 2011 Submitted. 
48. Wellman LL, et al. Antagonizing corticotropin releasing factor 1 receptors (CRF1R) in the Basolateral Amygdala (BLA) Attenuates the Effect of Footshock Training on Sleep in Rats. SLEEP. 2010; 33:A44. Abstract.

49. van Bogaert MJ, et al. Mouse strain differences in autonomic responses to stress. Genes Brain Behav. 2006; 5(2):139-49. [PubMed: 16507005]

50. Veening JG, et al. Stress-induced hyperthermia in the mouse: c-fos expression, corticosterone and temperature changes. Prog Neuropsychopharmacol Biol Psychiatry. 2004; 28(4):699-707. [PubMed: 15276696]

51. Singer R, et al. Hyperthermia induced by open-field stress is blocked by salicylate. Physiol Behav. 1986; 36(6):1179-82. [PubMed: 3725924]

52. Briese E, De Quijada MG. Colonic temperature of rats during handling. Acta Physiol Lat Am. 1970; 20(2):97-102. [PubMed: 5529391]

53. Zethof TJ, et al. Stress-induced hyperthermia in mice: a methodological study. Physiol Behav. 1994; 55(1):109-15. [PubMed: 8140153]

54. Clement JG, Mills P, Brockway B. Use of telemetry to record body temperature and activity in mice. J Pharmacol Methods. 1989; 21(2):129-40. [PubMed: 2716336]

55. Krarup A, et al. Evaluation of surrogate markers of impending death in the galactosaminesensitized murine model of bacterial endotoxemia. Lab Anim Sci. 1999; 49(5):545-50. [PubMed: 10551457]

56. Morimoto A, et al. The central role of corticotrophin-releasing factor (CRF-41) in psychological stress in rats. J Physiol. 1993; 460:221-9. [PubMed: 8487193]

57. Nakamori T, Morimoto A, Murakami N. Effect of a central CRF antagonist on cardiovascular and thermoregulatory responses induced by stress or IL-1 beta. Am J Physiol. 1993; 265(4 Pt 2):R8349. [PubMed: 8238454]

58. Hauger RL, et al. Corticotropin releasing factor (CRF) receptor signaling in the central nervous system: new molecular targets. CNS Neurol Disord Drug Targets. 2006; 5(4):453-79. [PubMed: 16918397]

59. Steriade, M.; McCarley, R. Brainstem Control of Wakefulness and Sleep. Plenum Press; New York: 1990.

60. Van Bockstaele EJ, Colago EE, Valentino RJ. Amygdaloid corticotropin-releasing factor targets locus coeruleus dendrites: substrate for the co-ordination of emotional and cognitive limbs of the stress response. J Neuroendocrinol. 1998; 10(10):743-57. [PubMed: 9792326]

61. Hammack SE, et al. The role of corticotropin-releasing hormone in the dorsal raphe nucleus in mediating the behavioral consequences of uncontrollable stress. J Neurosci. 2002; 22(3):1020-6. [PubMed: 11826130]

62. Hammack SE, et al. Low doses of corticotropin-releasing hormone injected into the dorsal raphe nucleus block the behavioral consequences of uncontrollable stress. Behav Brain Res. 2003; 147(1-2):55-64. [PubMed: 14659570]

63. Hammack SE, et al. Corticotropin releasing hormone type 2 receptors in the dorsal raphe nucleus mediate the behavioral consequences of uncontrollable stress. J Neurosci. 2003; 23(3):1019-25. [PubMed: 12574432]

64. Grahn RE, et al. Activation of serotonin-immunoreactive cells in the dorsal raphe nucleus in rats exposed to an uncontrollable stressor. Brain Res. 1999; 826(1):35-43. [PubMed: 10216194]

65. Bland ST, et al. Prefrontal cortex serotonin, stress, and morphine-induced nucleus accumbens dopamine. Neuroreport. 2004; 15(17):2637-41. [PubMed: 15570168]

66. Bland ST, et al. Stressor controllability modulates stress-induced serotonin but not dopamine efflux in the nucleus accumbens shell. Synapse. 2003; 49(3):206-8. [PubMed: 12774305]

67. Tsuda A, et al. Stressor controllability and brain noradrenaline turnover in rats. Yakubutsu Seishin Kodo. 1987; 7(3):363-74. [PubMed: 3442130]

68. Liu X, Tang X, Sanford LD. Stressor controllability and Fos expression in stress regulatory regions in mice. Physiol Behav. 2009; 97(3-4):321-6. [PubMed: 19275908]

69. Natelson BH. Stress, hormones and disease. Physiol Behav. 2004; 82(1):139-43. [PubMed: 15234602] 
70. Baratta MV, et al. Controllable versus uncontrollable stressors bi-directionally modulate conditioned but not innate fear. Neuroscience. 2007; 146(4):1495-503. [PubMed: 17478046]

71. Dohrenwend BP. The role of adversity and stress in psychopathology: some evidence and its implications for theory and research. J Health Soc Behav. 2000; 41(1):1-19. [PubMed: 10750319]

72. McLaren S, Crowe SF. The contribution of perceived control of stressful life events and thought suppression to the symptoms of obsessive-compulsive disorder in both non-clinical and clinical samples. J Anxiety Disord. 2003; 17(4):389-403. [PubMed: 12826088]

73. Bryant RA, et al. Sleep disturbance immediately prior to trauma predicts subsequent psychiatric disorder. Sleep. 2010; 33(1):69-74. [PubMed: 20120622] 
Highlights

Rapid eye movement sleep (REM) is increased after controllable stress. > Corticotropin releasing factor (CRF) blocks increased REM after controllable stress. > Antagonizing CRF does not alter REM after controllable stress. $>$ Stress-induced hyperthermia is not significantly altered by CRF or CRF antagonist. >Central CRF is an important regulator of stress-induced alterations in REM. 
A.

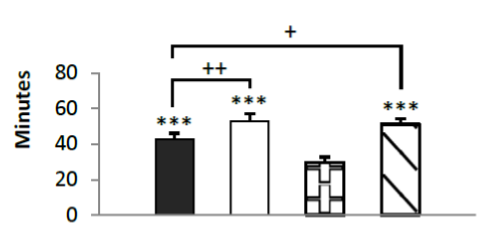

C.

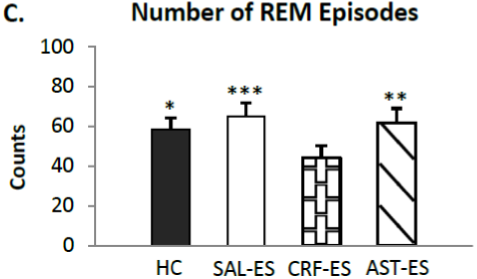

B.
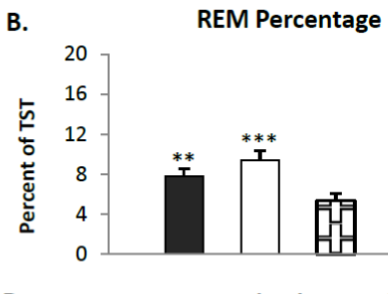

D.

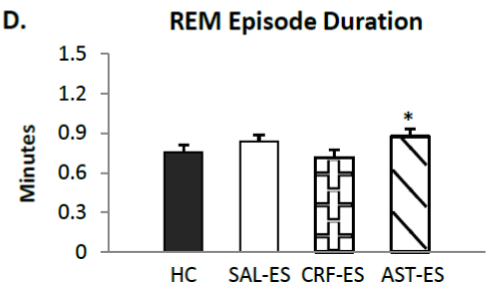

\section{Figure 1.}

Total $20 \mathrm{~h}$ REM parameters for handling control (HC), ICV microinjections of saline prior to escapable shock (SAL-ES), corticotropin releasing factor prior to ES (CRF-ES) and astressin prior to ES (AST-ES). A. total REM. B. REM percentage (total REM time/total sleep time * 100). C. number of REM episodes. D. REM episode duration. Significant differences relative to CRF-ES: $* \mathrm{p}<0.05 ; * * \mathrm{p}<0.01 ; * * * \mathrm{p}<0.001$. Significant differences relative to $\mathrm{HC}:+\mathrm{p}<0.05 ; * * \mathrm{p}<0.01$ (Tukey test). Values are means \pm SEM. 

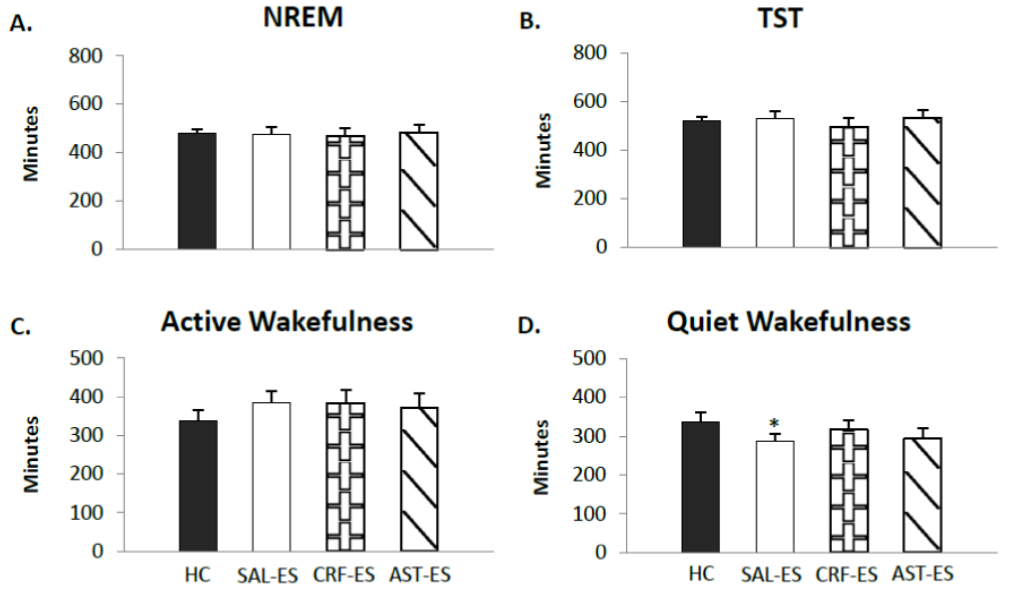

Figure 2.

Selected sleep and wakefulness parameters for handling control (HC), ICV microinjections of saline prior to escapable shock (SAL-ES), corticotropin releasing factor prior to ES (CRF-ES) and astressin prior to ES (AST-ES). A. Total NREM. B. Total sleep time (TST). C. Active wakefulness. D. Quiet wakefulness. Significant differences relative to HC: $* \mathrm{p}<0.05$ (Tukey test). Values are means \pm SEM. 


\section{Body Temperature}

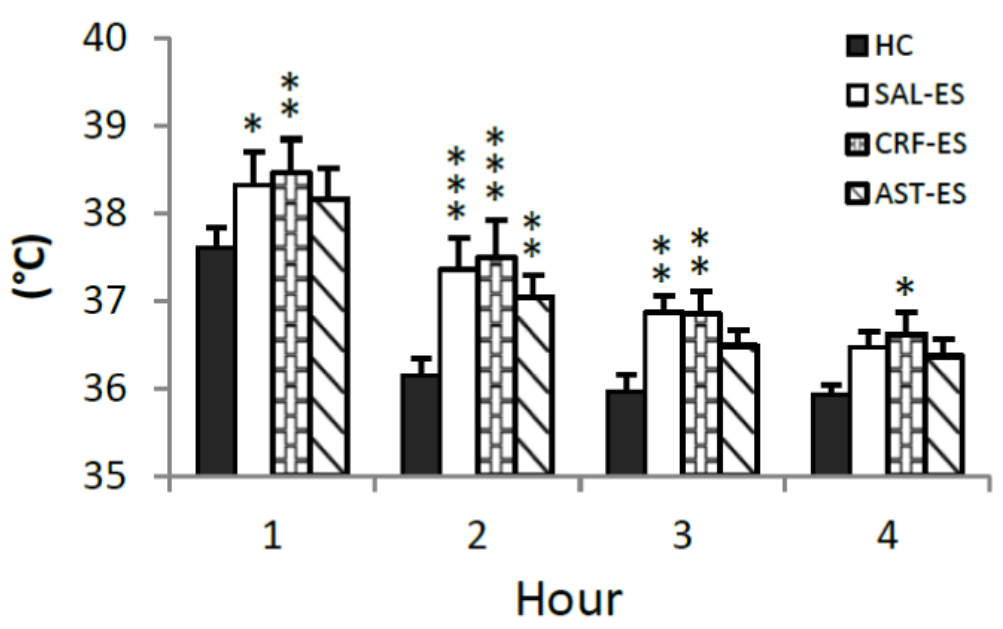

Figure 3.

Average core body temperature plotted hourly for the first $4 \mathrm{~h}$ of the $20 \mathrm{~h}$ recording period for handling control (HC), ICV microinjections of saline prior to escapable shock (SAL-ES), corticotropin releasing factor prior to ES (CRF-ES) and astressin prior to ES (AST-ES). Significant differences compared to HC: $* \mathrm{p}<0.05$; $* * \mathrm{p}<0.01 ; * * * \mathrm{p}<0.001$ (Tukey tests). Values are means \pm SEM. 


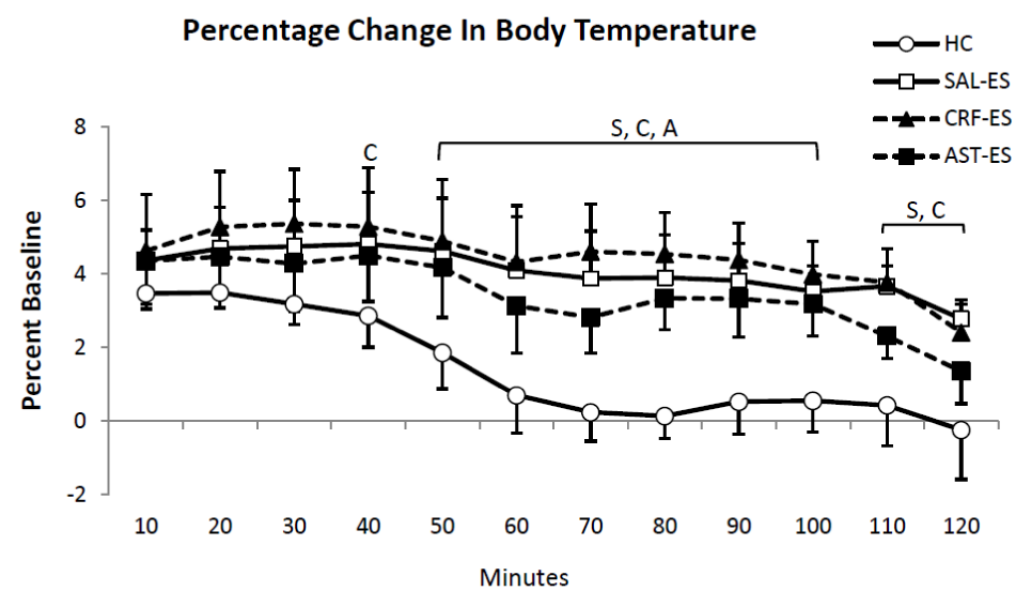

Figure 4.

Percent changes of core body temperature relative to baseline [(treatments - baseline)/ baseline $* 100$ ] presented in 10 min intervals for the first $2 \mathrm{~h}$ of recording for handling control (HC), ICV microinjections of saline prior to escapable shock (SAL-ES), corticotropin releasing factor prior to ES (CRF-ES) and astressin prior to ES (AST-ES). The letters S, C and A in the plot represent SAL-ES, CRF-ES and AST-ES, respectively, and indicate significant differences from $\mathrm{HC}, \mathrm{p}<0.05$ or greater (Tukey tests). Values are means \pm SEM. 